Author-produced version of the article published in Journal of Hydrology 2006, 327(1-2), 186-199.

The original publication is available at http://www.sciencedirect.com/ doi : 10.1016/j.jhydrol.2005.11.026 


\section{$1 \quad$ Modeling floods in a dense urban area using 2D shallow water equations}

$$
\text { Mignot } E^{1} \text {, Paquier } A^{2} \text {., Haider } S^{3} \text {. }
$$

\section{Abstract}

5 A code solving the 2-D shallow water equations by an explicit second-order scheme is used to 6 simulate the severe October 1988 flood in the Richelieu urban locality of the French city of Nîmes. A 7 reference calculation using a detailed description of the street network and of the cross sections of the streets, considering impervious residence blocks and neglecting the flow interaction with the sewer network provides a mean peak water elevation $0.13 \mathrm{~m}$ lower than the measured flood marks with a standard deviation between the measured and computed water depths of $0.53 \mathrm{~m}$. Sensitivity analysis of various topographical and numerical parameters shows that globally, the results keep the same level of accuracy, which reflects both the stability of the calculation method and the smoothening of results. However, the local flow modifications due to change of parameter values can drastically modify the local water depths, especially when the local flow regime is modified. Furthermore, the flow distribution to the downstream parts of the city can be altered depending on the set of parameters used. Finally, a second event, the 2002 flood, was simulated with the calibrated model providing results similar to 1988 flood calculation. Thus, the article shows that, after calibration, a 2-D model can be used to help planning mitigation measures in a dense urban area.

Keywords : Flood; 2D shallow water equations; Calibration; Urban areas; Sensitivity analysis.

${ }^{1} \mathrm{PhD}$ student, Cemagref, Hydrology-Hydraulics Research Unit, 3 bis quai Chauveau, CP220, 69336 Lyon Cedex 09, France.

Email:mignot@lyon.cemagref.fr,ph. : +33 472208775,fax+33 478477875

${ }^{2}$ Researcher, Cemagref, Hydrology-Hydraulics Research Unit, 3 bis quai Chauveau, CP220, 69336 Lyon Cedex 09, France.

Email : andre.paquier@cemagref.fr,ph. : +33 472208775,fax +33 478477875

${ }^{3}$ Assistant Profesor, National Institute of Transportation, Risalpur, NWFP, Pakistan 


\section{Introduction}

3 Surface flood modeling in urban environment is a challenging task for a number of reasons: the

4 presence of a large number of obstacles of varying shapes and length scales, the storages in the

5 buildings, the complex geometry of the city, etc. However, if the intensity of the event is strong

6 enough and the domain is a dense urban zone, it can be assumed that the majority of the flow passes

7 by the streets and the junctions. The flow in the streets is mostly one-dimensional except near the

8 junction but it was shown that at junctions (Weber et al., 2001) and bifurcations (Neary et al., 1999),

9 the flow is basically 3D. Thus (Huang et al., 2002) performed a 3D calculations of flow at a junction

10 and found that the results agreed with the measurements. However, (Khan et al., 2000) and (Shettar

11 and Murthy, 1996) showed that 2-D models can simulate the water surface and velocity field near the

12 crossing and predict the distribution at a subcritical bifurcation.

13 Looking at the available literature in surface urban flood simulations, this statement seems accepted by 14 many authors as it appears that most studies use 2-dimensional models. (Ishigaki et al., 2004) for an 15 experimental urban flood case study and for real cases use full shallow water equation models or 16 simplified models neglecting the inertial terms (Chen et al., 2004) to simulate urban floods. For these 17 real cases, the origin of the flood can be the overflow of a river (Calenda et al., 2003), the invasion of 18 land drainage flow from the upstream hills (Aronica and Lanza, 2005; Haider et al., 2003), the rain 19 storm event on the modeled area or sewer drainage failure (Hsu et al., 2000; Mark et al., 2004; Schmitt 20 et al., 2004). The building blocks can be either considered impervious or numerical methods for 21 introduction of flow in the building blocks are proposed (Inoue et al., 2000). In most of the urban 22 flooding numerical simulation references, only few validation data was available and so the quality of 23 the simulations could not be precisely assessed. Furthermore, calibration processes and the influence 24 of the chosen parameters were not proposed in the previously cited references.

Email : sdhaider@hotmail.com, ph. : +92 923636211, fax : +92 923631594 
1 In order to examine the conditions of use of a 2-D model, the authors decided to investigate the case of

2 the dense city of Nîmes that experienced two recent dramatic flood events in a topographical context

3 of steep slopes and high velocities. The explicit finite volume numerical code "Rubar 20" (Paquier A.,

4 1995; Paquier A., 1998) was used to solve the full 2D shallow water equations. The October 1988

5 flood was used as a base simulation in order to discuss the sensitivity of such a calculation to

6 particular modeling features: the level of detail in the description of the streets, the description of

7 specific urban structures, the boundary conditions, the values of some numerical parameters. Then

8 modeling of a second event (the September 2002 flood) was performed in order to validate the

9 calibration of the model. Finally, a conclusion about the calibration process of such a model and its

10 technical application for planning emergency measures is undertaken.

12 The governing equations and the numerical scheme

13 The system of 2D shallow water equations consists of 3 equations: one equation for continuity and two 14 equations for the conservation of momentum in the two orthogonal directions.

$15 \quad \frac{\partial h}{\partial t}+\frac{\partial(h u)}{\partial x}+\frac{\partial(h v)}{\partial y}=0$

$16 \frac{\partial(h u)}{\partial t}+\frac{\partial\left(h u^{2}\right)}{\partial x}+\frac{\partial(h u v)}{\partial y}+g h \frac{\partial h}{\partial x}=-g h \frac{\partial z b}{\partial x}-g n^{2} \frac{u \sqrt{u^{2}+v^{2}}}{h^{1 / 3}}+v_{e f} \frac{\partial}{\partial x}\left(h \frac{\partial u}{\partial x}\right)+v_{e f} \frac{\partial}{\partial y}\left(h \frac{\partial u}{\partial y}\right)$

$17 \frac{\partial(h v)}{\partial t}+\frac{\partial(h u v)}{\partial x}+\frac{\partial\left(h^{2}\right)}{\partial y}+g h \frac{\partial h}{\partial y}=-g h \frac{\partial z b}{\partial y}-g n^{2} \frac{v \sqrt{u^{2}+v^{2}}}{h^{1 / 3}}+v_{e f} \frac{\partial}{\partial x}\left(h \frac{\partial v}{\partial x}\right)+v_{e f} \frac{\partial}{\partial y}\left(h \frac{\partial v}{\partial y}\right)$

18 In which $h$ is water depth, $u$ and $v$ are velocities along horizontal $x$ and $y$-axis, $z_{b}$ is bottom level, $n$ is

19 Manning's roughness coefficient, $g$ is gravity acceleration and $v_{\text {ef }}$ is effective cinematic viscosity.

20 Usually, it is assumed that the viscosity is constant throughout the flow field. However, the model

21 (simpler than the $k-\varepsilon$ model) defined by the following relation was also tested:

$v_{e f}=k h_{u}^{*}$ 
1 In which $k$ is a non-dimensional coefficient and the bottom friction velocity $u^{*}$ is approximated by (5)

2 instead of the usual relation from the friction coefficient in order to enhance the variations of the water 3 surface elevation.

$4 \quad u=\sqrt{g h \sqrt{\left(\frac{\partial\left(z_{b}+h\right)}{\partial x}\right)^{2}+\left(\frac{\partial\left(z_{b}+h\right)}{\partial y}\right)^{2}}}$

5 In the "Rubar 20" code (Paquier A., 1995; Paquier A., 1998), the conservative form of the equations 6 (1) to (3) above are solved on a grid constituted of quadrilaterals and triangles using an explicit 7 second-order numerical scheme that is adapted from MUSCL approach (VanLeer B., 1979). The 8 selected scheme is able to calculate highly unsteady flows and can treat the transitions between 9 subcritical and supercritical flows as ordinary points. Drying and wetting of cells are treated 10 specifically in the following way: a cell is considered as dry as long as the water volume entering an 11 originally dry cell during one time step provides an average water depth in the cell below a minimal 12 value $(0.01 \mu \mathrm{m}$ in present study). During drying process, a similar option is used and leads to a mass 13 conservation error that is usually less than $0.01 \%$ of the total mass. This numerical scheme is 14 generally stable under the Courant Friedrichs Levy condition that limits the Courant number to values below unity. However, in the case of steep slopes, the time step should be further restricted; thus, 16 modeling requires high calculation power.

17 The validation of the numerical scheme on very unsteady flows (against analytical solutions and 18 experimental data sets) was extensively performed through the IAHR group on dam-break wave and 19 during the CADAM and IMPACT European research projects that included comparisons with other 20 numerical codes. Some of these experiments included dam beak wave calculation in simple 21 rectangular channels, in more irregular topography domains with introduction of blocks to simulate 22 obstacles or buildings (Mignot and Paquier, 2003a; Mignot and Paquier, 2003b) or on a real urban 23 flood situation (Mignot and Paquier, 2004). All these tests proved the relevance of "Rubar 20" code to 24 solve 2D shallow water equations in rapid flow and complex topographic situations. To complete the 25 code validation in the domain of urban floods, some experimental tests of four rectangular channel 
1 junction flows were performed in the INSA Fluid Mechanics Laboratory in Lyon (France). Precise

2 measurements of the observed flow patterns of supercritical junction flows were performed and 3 compared to the water depths computed with "Rubar 20" (Mignot et al., 2005b). It appeared that the 4 code was able to predict with fair agreement the structure of the flow and the locations of the specific 5 flow structures such as the hydraulic jumps, the recirculation zones and the eddying (Mignot et al., $62005 a)$.

7

8 The 1988 flood and the presentation of the studied area

9 Nîmes is a French city located in a plain just downstream from 7 hills surrounding its northern area.

10 Since 1350 , many records of severe floods have been recorded in the city and the flood of October, $3^{\text {rd }}$

111988 in Nîmes was among the most dramatic observed events. It was caused by a rainstorm that 12 generated up to $420 \mathrm{~mm}$ of rain in about eight hours on the northern hills (Desbordes et al., 1989) and 13 led to the overflow of the watercourses to the north of the city and the subsequent inundation of 14 various localities with water depths up to 3 meters, causing extensive damages to property and human 15 life (Bonneaud, 2002). (Desbordes et al., 1989) evaluated the return period of this event to 150 to 250 16 years.

17 The studied area known as "Richelieu", located in the Northeastern part of the city of Nîmes was one 18 of the most dramatically affected zones. The dimensions of the area are about $1400 \mathrm{~m}$ along the north19 south axis that is also the main principal flow direction, and a variable East-West width with a 20 maximum and minimum of about $1050 \mathrm{~m}$ and $220 \mathrm{~m}$ respectively. A railway embankment runs all the 21 way along the northern side, the western flanks is formed by hills and the eastern flank is constituted by an impervious railway station (Figure 1). One particularity of the city of Nîmes is that no river crosses the city, indeed when it rains on the region, the flow drained by the temporary watercourses enters the urban area and flows in the underground watercourses until reaching the Vistre river

25 downstream from the city. However, when the discharges in the watercourses becomes larger than 26 their conveyances, overflows occur upstream from the city and the water enters its Northern parts 
1 following the natural slope (north to south), flowing within the streets. "Richelieu" is one of these

2 localities, where the flow can enter through several street underpasses located in the railway

3 embankment. The drop in ground level in the studied area is respectively 20 and $15 \mathrm{~m}$ from the

4 western and eastern underpasses (Figure 1) to the southern boundary, which represents an average

5 slope higher than $1 \%$. The upstream part of the city (Figure 1) is composed of large building blocks

6 areas such as the military barracks and the hospital with wide streets and few crossroads. The central

7 part is a rather regular network with narrow streets (5 to 8 meters wide) and right angle crossings

8 between them. This area is interesting due to the relative abundance of the flood marks that

9 demonstrates an average peak water depth of about one and a half meter. However, photos show that,

10 in some specific points, waves occurred and water surface rose along the buildings, which means some

11 uncertainties in the peak water level, confirmed by differences between couples of close water marks

12 Finally, the urban structure of the Southern part is intermediate between the Northern and Central part,

13 with average width streets and still a high main North-South slope.

15 Available data for the 1988 flood and their preliminary processing

16 The Public works department of the Gard County and the Technical Services of Nîmes city supplied

17 the necessary primary data for the simulations. It included:

18 (a) About 200 cross-sectional profiles for the 60 streets located in the studied area. A typical street profile (Figure 2) contained 11 points including the top and foot of both side walls (points 1

(b) A map of the area showing the limits of the flooded area, the land use (built-up places...) and some complementary ground elevations. The 99 flood mark elevation points measured immediately after the 1988 flood were also noted on the map showing the measurement locations. $85 \%$ of these flood marks are located in crossroads at the corner between two building walls and the remaining $15 \%$ are located within the streets on the façade of a building. 
1 (c) Rainfall data measured at various locations around the area.

2 BCEOM French consulting firm performed an hydrological modeling (BCEOM et al., 2004) on the 3 upstream basins $\left(10 \mathrm{~km}^{2}\right.$ and $\left.3.5 \mathrm{~km}^{2}\right)$ starting from rainfall measurements in order to compute 4 hydrographs at the upstream border of the Richelieu domain. The model is based on a conceptual 5 linear tank approach similar to GR4 model (Perrin et al., 2003); it considers separately the 6 hydrological processes on the urban areas and the runoff on grass land of the upstream basins. Then, 7 for various hydrological events, the model was calibrated to fit with the observations of flood marks at 8 the upstream end of the Richelieu area (railway line) and more upstream.

9 In this step, the sewage network was taken into account, the discharge capacity of the sewage network $10\left(4 \mathrm{~m}^{3} / \mathrm{s}\right.$ and $7 \mathrm{~m}^{3} / \mathrm{s}$ for the pipes at the Western and Eastern domain entrance respectively) was 11 subtracted form the calculated surface inflow hydrographs. Nevertheless, it appears that the maximum capacity of the sewage network is less than $10 \%$ of total peak discharge in 1988 , which is of the order of the hydrological results uncertainties. Furthermore, when the upstream hydrograph reached the studied area, the sewage network was already almost full due to the rain falling on the city. The result of this hydrological modeling consists in two discharge hydrographs that can be used for inputs at the northwest and northeast upstream boundary of the model. The hydrographs span a period of 13 hours

17 with a time step of 15 minutes (Figure 3).

18 The cross-sectional street profiles (Figure 2) constituted the basic structure of the calculation mesh. In order to obtain a complete description of the city, a linear interpolation between the intersecting streets permitted to obtain the input and output cross sections of each street junction. Then the generation of the 121 points of each crossroad (11 points from both joining streets) was achieved by interpolating

22 between the input and output sections. Additional points and information were introduced for the mesh 23 of the "complex" topographical crossings. Building blocks were considered as watertight and details 24 about them were not introduced. Furthermore, the sewage network was not taken into account in the 25 hydraulic study, assuming that the exchanges between the surface and the network could be neglected 
1 compared to the flow rates and water depths in the streets. From this construction, the DEM contains

2 about 25,000 points for the streets, each one described by its three coordinates $x, y, z$.

4 Reference calculation

5 The basic calculation mesh is generated keeping all the points from the DEM and adding extra points 6 along the streets. The specification of an average space step of 25 meters along the streets generally 7 leads the mesh generator to interpolate less than five additional sections along the streets. This choice 8 of a rather long space step came from the hypothesis that, except in (or close to) the crossings, the 9 flow is predominantly 1D. Furthermore, this reduces the calculation time but restricts the possibilities to include small scale urban structures and to simulate the complexity of the flow in the streets in the 11 vicinity of the junctions. The mesh consists of 100 quadrangles in each crossroad and between 30 and 1260 quadrangles in each street reach ( 10 across each street multiplied by 3 to 6 along the street).

13 The parameters were set to their default values that a priori was considered as the best initial way to 14 obtain suitable results. Friction was estimated to have uniform Manning's coefficient on the whole area accounting for the actual flow friction on the road pavement and the building walls and for the interaction of the flow with various small scale obstacles (trees, cars, bus stops...). The corresponding

17 information available in the literature for 2D simulations in street networks can vary much : Manning 18 coefficients used were $\mathrm{n}=0.01$ (Aronica and Lanza, 2005), $\mathrm{n}=0.015$ (Nania, 1999), $\mathrm{n}=0.025$

19 (Gourbesville and Savioli, 2002), $\mathrm{n}=0.043$ (Inoue et al., 2000) and $\mathrm{n}=0.08$ (Calenda et al., 2003).

20 Values of friction coefficient $n=0.025 \mathrm{~s}^{-1 / 3}$ and diffusion coefficient of $0.1 \mathrm{~m}^{2} / \mathrm{s}$ were chosen for our 21 case. The calculation was performed with a fixed time step of $0.01 \mathrm{~s}$. The hydrographs presented in Figure 3 constitute the upstream boundary conditions at both streets passing below the railway embankment at the northern end of the domain. In order to limit the calculation time, only the initial

2410 hours of the hydrographs were considered for the simulation. This duration is sufficient to capture 25 the flood dynamics and to obtain the peak water levels at any point in the modeled area. Also, the rain 26 on the domain is neglected. A critical flow boundary condition (Froude number equal to one) was 
1 fixed at the downstream ends of the model, i.e. the six downstream streets ( $S 3$ to $S 7$ on Figure 1)

2 oriented from North to South, the three streets ( $S 8$ to $S 10$ ) oriented West to East and the three ( $S 1$ and

3 S2 on Figure 1) oriented East to West. An additional outlet with free flow condition was added in a

4 street at the Eastern end of the domain (S11) in order to take into account overflows to a railway line

5 located more than one meter below the model boundary.

6 The domain is initially dry and at the beginning of the event, both hydrographs invade the area on each

7 side of the northern part of the domain. Part of the Eastern discharge flow turns towards the Eastern

8 limit of the area and then leaves the calculation domain through the exit S11 located in Pitot street. On

9 the other hand, a large part of both upstream flows joins at the Faita/Sully crossroad and spreads in the

10 Central zone narrow streets and into the Southern part of the domain before leaving the area at the

11 Southern limits. Most of the streets are flooded by the flow from the upstream to the downstream

12 reach of the street, however, some streets such as the Western part of Pitot street are filled through

13 their downstream reach due to backwater effects. The time of maximum water depth in most places

14 corresponds to the peak of the Eastern hydrograph (Figure 3), which intensity is much larger than the

15 Western hydrograph. At the flood peak ( $\mathrm{t} \sim 4.1$ hours), high velocities (3 to $4 \mathrm{~m} / \mathrm{s}$ ) and supercritical

16 regime flow occur along the main North-South slope directions especially in the wide streets and low

17 velocities $(0.5-0.7 \mathrm{~m} / \mathrm{s})$ with subcritical regimes appear in the streets aligned West to East (Figure 4).

18 In the crossroads, the flow is generally complex and both regimes can be observed. On the other hand,

19 the maximum depths appear in two locations : in the Faita street at the sudden street narrowing and in

20 the Faita/Sully crossroad (Figure 5). Those two locations also correspond to low velocity zones.

22 Comparison of calculation results with observations

23 First it appears that the extent of the flooded area (Figure 5) is in agreement with the limits supplied by

24 the officials of the Gard County as it is mostly determined by topographical limits (hills and building 25 walls).

26 In Nîmes, the flood marks were recorded on the building walls. However, in our numerical model, no 27 water depth calculation is performed on the cell edges and the 99 flood marks had to be compared with 
1 the peak water depths calculated at the center of the nearest cell, which is on the "pedestrian walk"

2 cell. These cells are named "comparison cells" in the following paragraphs. The results of the peak

3 water depths comparison are given in Table 1 . About $40 \%$ of the peak water depths are overestimated

4 and $60 \%$ underestimated by the calculation, the largest difference being about 1.6 meters and the

5 average absolute difference is $41 \mathrm{~cm}$.

6 The model appears to be calibrated on the Northern part of the domain (Table 1) where the average

7 difference between the computed peak water depths and the flood marks is close to 0 , even though the

8 standard deviation is large $(56 \mathrm{~cm})$. The peak water depths at two main locations appear not to be

9 fairly estimated : the Eastern entry (zone $A$ ) where the water depth of the flow below the railway

10 embankment is underestimated and upstream from one of Faita crossroads (zone B) where the sudden

11 reduction of the street width may not be represented accurately in the interpolated mesh. In the Central

12 part of the domain, the computed peak water depths in the narrow streets are strongly underestimated

13 (zone C) by an average of $43 \mathrm{~cm}$ (Table 1). This underestimate may be due to the street characteristics:

14 narrow streets with many parked cars reducing the flowing section and increasing locally the friction.

15 Finally, the peak water depths in the Southern area is slightly overestimated ( $\mathrm{dh}=13 \mathrm{~cm}$ in Table 1$)$;

16 however this overestimate is mainly due to the overestimate of the water depth in one street (zone $\mathrm{D}$ in

17 Figure 6) where topographical uncertainties or other flow features may have occurred.

18 The histogram (Figure 7) showing the peak water depth differences between calculation

19 results and on-site measurement is centered around 0 proving that no specific bias is 20 encountered.

\section{Sensitivity test cases}

23 The influence of various parameters was tested on the 1988 flood event by altering just one parameter 24 in each calculation compared to the reference case simulation, by checking the induced modifications 25 in the numerical results and explaining the origins of the changes. From a general point of view, 26 Figure 8 shows that the shapes of the computed limnigrams remain all quite similar but, when looking 
1 at the error table (Table 1), it appears that the prediction of the peak water depth at the 99 comparison

2 locations (flood mark locations) can be strongly affected by the choice of the parameters set.

4 Case 1 : Inflow and storage of water

5 Case $1 \mathrm{~A}$. In order to check the influence of the hydrological calculation uncertainties, the input

6 discharge hydrographs were increased by an amount of $20 \%$ at each time step compared to the

7 reference calculation. The consequence of such increase in upstream input condition is an average

8 increase of water depth (of $12.5 \mathrm{~cm}$ ), with a larger increase in the upstream zone $(17 \mathrm{~cm})$ than the

9 Central and downstream zones $(10 \mathrm{~cm}$ each) because of higher damping of peak discharge 10 downstream.

11 Case 1B. In the reference case, the only water input considered is the drainage from the upstream 12 watersheds. In case $1 \mathrm{~B}$, the rain falling on the streets and building blocks (supposed to reach 13 instantaneously the closest street cells) was added. Although the intensity of the rain is very high

14 (maximum of $61 \mathrm{~mm} / \mathrm{h}$ ), the rain water volume remains low $\left(212,000 \mathrm{~m}^{3}\right)$ compared to the input 15 hydrographs volume $\left(3,600,000 \mathrm{~m}^{3}\right)$ and its influence is very limited : the peak water depths are 16 increased everywhere by about $4 \mathrm{~cm}$, i.e. $4 \%$. The strongest influences are observed in the downstream 17 part of the domain (due to cumulative effects) and in the streets filled by backwater effects at the downstream reach (Pitot street).

19 Case 1C. In the reference case, it was assumed that all the buildings were impervious and that water could not be stored in caves, courtyards, dead end streets... However, witnesses and photographs

21 reveal that the water actually invaded most of these areas reducing the volume of water flowing in the streets. Among the storage areas in the domain, the military barracks area represents the largest storage volume available and a calculation with its gate completely open was launched. The computed volume stored at the flood peak is about $80,000 \mathrm{~m}^{3}$ which is very small compared to the input volume of $3,600,000 \mathrm{~m}^{3}$. Consequently, apart from local flow modifications near the gate, only a very small 26 reduction of computed peak water depths (about $1 \mathrm{~cm}$ ) occurs in the areas downstream from the 27 military barracks. 


\section{Case 2 : Friction and viscosity numerical coefficients}

3 Case 2 A. Energy is dissipated numerically through the bottom friction and diffusion that should 4 mainly reflect both the effect of turbulence and the heterogeneity along the vertical direction. In order 5 to check the influence of the diffusion coefficient $v_{e f}$ in equations (2) and (3), we simulated the event 6 applying, on the one hand a 0 diffusion coefficient and on the other hand a coefficient depending on 7 the water depth as presented in equation (4) with $k=10^{-2}$. For this latter value $60 \%$ of the cells have an 8 equivalent diffusion coefficient $v_{e f}$ larger than $0.1 \mathrm{~m}^{2} / \mathrm{s}$ at the flood peak. The results from these two 9 calculations show that the diffusion parameter has a very small influence on the computed flow, the 10 average absolute peak water depth modification being about $3 \mathrm{~cm}$ on the studied area.

11 Case 2B. Identifying the exact friction coefficient is almost impossible as this coefficient stands for the sum of various sources of resistances such as bottom friction, friction on the walls or due to their irregularities, small scale obstacles to the flows. The $n=0.025$ Manning coefficient first chosen was 14 changed to $n=0.033$.

15 1) Overall, this larger friction tends to increase all the computed peak water depths of about $10 \mathrm{~cm}$.

16 2) Nevertheless, it also modifies strongly the flow structure in the vicinity of Faita/Sully crossroad 17 with the consequence of altering the flow distribution at this junction. Indeed this larger friction coefficient lowers the flow discharge - thus decreasing the peak water depths - in the downstream Faita street and modifies the flow distribution in the downstream boundary streets. Consequently, the computed flood in the whole Southern area is affected.

21 3) Finally, the change in friction coefficient slightly alters the predicted flow structure in most crossroads and, in some cells, the flow regime can be changed between supercritical and subcritical conditions, hence strongly modifying the local computed water depths. For instance Figure 9 presents the flow regimes computed at one crossroad at the flood peak for the Reference case and Case 2B and shows that the flow in the comparison cell is supercritical for the Reference case and subcritical for 
1 computed during the event but for the Reference case, the water depth is lower than before $\mathrm{t}=3.8 \mathrm{~h}$ and

2 after $\mathrm{t}=4.8 \mathrm{~h}$ (Figure 10 ).

3 In the end, it appears that considering the $n=0.033$ friction coefficient, the underestimation of peak

4 water depths is decreased in the Central zone but then overestimations appear in the Northern zone and

5 increase in the Southern zone. Globally, the computed average peak water depth is less underestimated

6 than the reference case (Table 1) but then the model is not any more calibrated in the Northern zone

$7 \quad(\overline{d h}=17 \mathrm{~cm})$ and becomes more overestimated in the Southern zone.

8 Case 2C. The improvement of the results in the Central zone presented in the previous paragraph leads

9 us to consider different friction coefficients for the various zones of the urban area. The friction

10 coefficient in the narrow streets of the Central zone (all except Faita and Semard streets) is increased

11 to $n=0.05$ (and $n=0.025$ remains in the rest of the domain). Indeed, as the streets are narrower in this

12 zone, the relative importance of the building walls friction increases; moreover, the presence of many

13 parked cars creates a stronger resistance to the flow. As was expected, in the Central zone, the

14 velocities are decreased and the peak water depths increased, improving their comparison with the

15 flood marks (Table 1). This test proves that the friction parameter should be calibrated for each

16 homogeneous urban zone according to the potential friction due to the fixed and mobile (non

17 represented) obstacles and the street dimensions.

Case 3 : Downstream boundary conditions

20 Case $3 \Lambda$. The change of the numerical treatment of the downstream boundary condition from a critical

21 flow condition (Froude number $=1$ ) to a free condition (corresponding to a local zero discharge 22 gradient hypothesis in case the flow regime is subcritical, and no flow influence if the local flow is 23 supercritical) strongly alters the flow in the close vicinity of the domain downstream limit: the 24 computed flow depths are strongly increased and the flow distribution to the downstream streets is 25 highly modified. 
1 Case 3B. Besides, it was considered, in the reference case, that the flow could leave the studied

2 domain without being influenced by the further downstream parts of the city. However, a large part of

3 the city was flooded during the event and some backwater effects from the downstream neighbor

4 streets may have occurred especially around the flood peak. Then, a calculation was performed

5 assuming very strong downstream South-Eastern and South-Western urban zone influences : the flow

6 was prevented from leaving the domain through streets $S 1, S 2$ and $S 10$ (Figure 1). This drastic change

7 of downstream boundary condition has a strong effect on the flow in the whole Southern part of the

8 city : the peak water depths are increased in the closed streets ( $S 1, S 2$ and $S 10$ )due to a local storage

9 of water volume and also near the other downstream streets as more outflow discharge occurs. As a

10 result, the computed peak water depth becomes strongly overestimated both in the southern part of the

11 Central zone (due to backwater effects) and in the Southern zones (Table 1 and Figure 11).

12 To sum up, whereas the choice of numerical method to calculate the downstream boundary condition

13 has only a space influence on the computed flow limited to the last downstream streets, the choice of

14 the streets allowing outflow from the domain to the downstream zones can alter strongly the flow in

15 the whole downstream area up to the fourth street towards the upstream direction.

17 Case 4 : Topographical modifications without altering the mesh

18 Case 4A. In order to simplify the data processing or if the available topographical data are not precise 19 enough, one can assume the street sections as being flat, thus neglecting the real profile of the streets.

20 In order to check the influence of this simplification, the bottom elevation of each street node was set 21 equal to the corresponding street mid-point bottom elevation. Two tendencies are then observed for 22 the 99 comparison cells :

23 1) Globally, the water depths are increased by about $10 \mathrm{~cm}$ in the whole studied area. Indeed, 24 we remark that the water volume in the street is similar to the reference case and generally, on the 25 comparison cells both the water depth and water level are increased, see Figure 12. 
2) The topographical modification of the crossroads topography can affect strongly the local

2 flow and the flow regime can change with the consequence of strong local water depth modification

3 (see Figure 10).

4 Overall, it appears that the comparison between computed peak water depths and the flood marks is

5 improved in the underestimated zones, namely the Central zone and worsened in the Northern and

6 Southern zones.

7 Case 4B. Another important question in urban flood modeling is whether it is worth representing

8 precisely the topography of the complex crossroads (or squares). A calculation was made by

9 simplifying drastically the topography of the Faita/Sully crossroad (to which more than $75 \%$ of the

10 flood flow converges) considering that the junction between both streets is a simple quadrilateral area

11 obtained by interpolating both streets sections as for the other simple crossroads. As could be expected

12 the flow structures and thus the computed water depths within the crossroad are much affected.

13 Moreover, it appears that :

14 1) The water depths in the upstream streets are increased as the reduction of the flowing section 15 creates backwater effects towards the upstream area.

16 2) The flow distribution in the downstream streets of the crossroad is modified due to a change of the

17 flow pattern at the junction : the discharge in Faita street is increased by $31 \%$ whereas the discharge in

18 Sully street is decreased by $10 \%$. As a consequence, the peak water depths are globally increased in

19 Faita street and slightly decreased in Sully street.

20 Case 4C. Finally, when a large amount of small scale debris (cars, fences...) is available in a zone, 21 some important obstacles can form downstream. In order to check the influence of such an obstacle, an 22 impervious wall was set at the downstream end of a main slope street of the central area (dot line in 23 Figure 1). The following consequences are observed. First, a storage of water just upstream from the 24 obstacle causes a large increase of water depth in the street and backwater effects increasing the water 25 depths in the upstream streets. Also, the original discharge of this street is re-directed towards the 26 neighbor streets, also increasing the water depths. Finally, the water volume downstream from the 27 obstacle is reduced and the computed water depths are lowered. Overall, it appears that the strong 
1 influence of the obstacle is spatially restricted, the maximum discharges modification in the

2 downstream boundary streets is only $2 \mathrm{~m}^{3} / \mathrm{s}$ (i.e. $8 \%$ ). Nevertheless, for flood events as strong as the

31988 flood, several such obstacles can happen in various places and in the end can have a strong

4 influence on the peak water depths on the whole area.

6 Case 5 : Mesh density in a longitudinal direction (same profile description)

7 Two tests were performed to check the influence of the mesh density in the longitudinal street 8 direction without altering the mesh density of the streets profile and at the crossroads: The first test

9 (Case 5A) mesh consists on only one calculation cell in each street portion between two crossroads, 10 with the interest of reducing the calculation time. For the second test (Case 5B), the longitudinal mesh 11 comprises an average of 4 to 5 cells in each street. The comparison between the computed peak water 12 depths and the flood marks located in the streets has no meaning as the calculation points are too 13 different. Concerning the flood marks in the crossroads ( $85 \%$ of the marks), the absolute average peak water depths are almost not affected by the mesh refinement (absolute average change of $2.5 \mathrm{~cm}$ ) and only slightly affected (by about $8.5 \mathrm{~cm}$ ) when using the coarser longitudinal mesh. The causes for these modifications are: first, some local flow structure modifications in the junction along with some

17 changes of flow regimes as for cases $2 \mathrm{~B}$ and $4 \mathrm{~A}$ (Figure 10); then a modification of flow distribution 18 at Faita/Sully crossroad, increasing the South-Western flow rates and decreasing it in the South19 Eastern area and finally a strong change in backwater effect in Pitot street flooded by a downstream 20 filling.

\section{Case 6 : Simplification of street profile mesh}

23 Altering the number of points used in the street profiles leads to the generation of different meshes and 24 to a variation of the profile topography (Figure 13) seven (Case 6A), five (Case 6B), and four points 25 (Case 6C) were considered. In going from an 11-points cross-section to a 4-point cross-section, the 
1 number of wetted calculation cells at the crossroads decreases from 64 to 1 , and the amount of data

2 required to mesh the urban area and the calculation time is also reduced.

3 For all the simplifications of the street section (cases $6 \mathrm{~A}, 6 \mathrm{~B}$ and $6 \mathrm{C}$ ), a tendency similar as for case

$44 \mathrm{~A}$ (to a smaller extent) appears : the computed water depths are slightly increased on the whole 5 domain due to an increase of the average bottom elevation of the street section. Moreover, for the 46 points cross-sections case (and also 5-points in a smaller extent), another phenomenon is observed :

7 the small amount of cells in the crossroads simplifies drastically the flow structure. Then the local high

8 or low velocity areas within the junction disappear and only the average flow regime remains. For

9 instance, if the flow in the crossroad is mainly subcritical with a small supercritical area in a corner

10 (where the flood mark is located), then the 4-points cross-section case will compute an average

11 subcritical flow at the junction and thus overestimate the peak water depth (compared to the flood marks and the reference case results). This phenomenon observed at 5 comparison cells locations is

13 presented in Figure 14. The opposite phenomenon can also occur if the flow is globally supercritical in

14 the junction with just a small subcritical area. Besides, the local modifications in the computed flow 15 also influence drastically the flow at larger scales and in the 4-points section cases, it alters the flow 16 distribution to the downstream boundary streets as shown in Figure 15.

17 To sum up, it appears that the 7-points cross-section computation results show a very small peak water depths modification on the whole studied area whereas these results with 4-points and 5-points crosssection computation are very affected by the street profile mesh simplification (Table 1).

\section{Validation of the model calibration on the 2002 flood event}

Apart from the October 1988 flood, the September 2002 event was among the largest flood observed in the past decades in Nîmes. The event process was roughly similar to the 1988 case with a rainfall intensity much lower and thus an available volume also reduced. BCEOM company applied a similar hydrological method in order to obtain both input hydrographs. In this case, the 2002 sewer network capacities is of the order of the flow rates coming from the upstream watersheds $\left(6 \mathrm{~m}^{3} / \mathrm{s}\right.$ and $7 \mathrm{~m}^{3} / \mathrm{s}$ 
1 compared to $13 \mathrm{~m}^{3} / \mathrm{s}$ and $30 \mathrm{~m}^{3} / \mathrm{s}$ ) and both pipes capacities were subtracted from the original input

2 hydrographs. 28 flood marks were measured on building walls after this event, with an average peak

3 water recorded of about $30 \mathrm{~cm}$ and a maximum of $85 \mathrm{~cm}$ in Faita street.

4 The parameters set used in the 1988 reference case is used to simulate the 2002 event using the same

5 mesh with the appropriate input hydrographs (Figure 16). It appears from the computed results that the

6 flood dynamics is quite similar as the one described for the 1988 case, even though all water depths

7 are much lower. The comparison between the computed peak water depths and the flood marks is

8 given in Figure 17.

9 It appears that the errors in peak water depth computation are quite homogeneously 10 distributed in the studied area, and no spatial tendency can be observed. Indeed, contrary to 11 the former case, the water depths in the narrow streets network of the Central zones are not underestimated. Furthermore, the average error between computed and recorded peak water

13 depths is $\overline{d h}=-3 \mathrm{~cm}$ proving that the calibration of the model is accurate for the simulation of 14 the September 2002 flood event. However, the large standard deviation $\left(\sigma_{d h}=22 \mathrm{~cm}\right)$ shows 15 that some local phenomenon must have modified the flow locally. Indeed, with the lower 16 water depths in the streets, the small scale obstacles, topographical irregularities and storage 17 areas have a larger influence on the flow for this less extreme flood.

\section{Conclusions and recommendations}

2D shallow water equations in their complete form were solved to simulate the flood propagation through an urban area represented as a network of streets. Street profiles including its main structural elements were used to mesh the streets and crossroads. Other features such as obstacles (cars, bus stops...), flood water storage spaces (cellars, parkings...) were not considered but could be introduced

24 in order to obtain more realistic local results (Haider, 2001; Haider et al., 2003). A first case of severe urban flood (1988 case) for which the exchanges between the streets and the potential storage areas or 
1 the sewage network are globally negligible was used for calibration and in order to check the influence

2 of various numerical and topographical parameters on the computed flow. The numerical results

3 obtained show a standard deviation of about $50 \mathrm{~cm}$. This is rather high but reflects the uncertainty in

4 the flood marks, the insufficiency of the topographical data provided initially, and, may be, the local

5 influence of somewhat hazardous events such as blockages by cars or building walls irregularities for

6 instance. Concerning the sensitivity analysis, it appeared that some parameters had very limit effects

7 and others had larger effects on the flow structure and especially the computed peak water depths.

8 Furthermore, some parameter modifications have global, zonal or local influences. Table 2 sums-up

9 the impacts of the various parameters tested in this article but the conclusions will not necessarily be

10 the same in other flood situations.

11 Consequently, the following recommendations could be useful for modelers wishing to simulate a 12 severe urban flood in a dense urban area :

13 1) Special attention should be paid during the hydrological calculations to establish the input

14 hydrographs. Especially, the peak discharge of the hydrographs should be precisely calculated if the

15 first objective is to establish the map of the peak water depths on the area.

16 2) If the rain volume falling on the studied area or the storage volume available in the domain are

17 small compared to the input hydrographs volumes, their effects will be very small and it is not worth 18 representing them.

19 3) Different friction coefficients should be applied for the various homogeneous urban feature zone, 20 depending on the width of the streets and the fixed and mobile obstacles that may increase the 21 resistance to the flow.

22 4) Collecting information about the flooded areas just downstream from the studied zone is 23 important in order to set accurate limit boundary conditions at the downstream streets.

24 5) The refinement of the mesh to be used for the calculation depends strongly on the objectives of 25 the study. If the main objective is to have an overview of the flood dynamics, then a rough description 26 of the street profile seems accurate enough. In the case of the $1988 \mathrm{flood}$, the 5-points cross-section 27 points with 3 wetted cells longitudinally between two crossroads seem a good compromise. 
1 Nevertheless in this case, the modeler should keep in mind that a slight global water depth 2 overestimation (about $10 \mathrm{~cm}$ ) occurs on the whole studied domain due to the increased average street 3 profile bottom elevation. The main advantages of considering a coarse mesh is both to simplify the 4 topographical data collection on the area and to reduce the calculation time, often prohibitive when 5 trying to simulate precisely an urban flood. However, if information about local velocities and/or 6 water depths exists in order to use this data for model calibration, then a more precise description of 7 the streets is required. In this case, it seems that the representation of the gutters is not required and the 8 use of 7-points crossing-sections (4 wetted cells in the section), thus with 49 nodes and 32 wetted cells 9 in each crossroad should be accurate enough except in the complex crossroads where specific attention 10 have to be paid to mesh the local topography more precisely.

11 Finally, the calibrated model was validated on a second less extreme event: the September 2002 flood.

12 The results show a standard deviation of about $20 \mathrm{~cm}$, which is better than for the 1988 flood case but 13 is high compared to the average peak water depth in the area (about $30 \mathrm{~cm}$ ). One reason for this may

14 be the higher sensitivity of the model to the small scale irregularities of the topography.

15 These results on one particular flood case should be confirmed on other field or experimental cases 16 showing a similar complicated pattern of streets and crossings. However, it was shown that the use of 17 a code solving 2-D shallow water equations to assess flood risk in a city seems a convenient solution. 18 In the case of Nîmes, the results of such calculations are being used for the reorganization of buildings 19 in the Richelieu area for urban projects ("Hoche - Sernam" operations). The new urban planning are 20 taken into account to modify the mesh of the studied area and calculations with the calibrated model of 21 a flood event equivalent to the 1988 case permit to check the peak water depths modifications.

\section{Acknowledgements}

24 This study has been funded by French Ministry of Environment through the two projects of the 25 program "Flood Risks" entitled "Hydrological risk in the urban environment" and "Estimation of 
1 surface flows for an extreme flood in urbanized environment". Many thanks should also be addressed

2 to all the partners of these two projects.

3

4

5 Notations

6 dh difference between computed peak water depth and flood mark measurement

$7 \overline{d h}$ average of $\mathrm{dh}$

$8 \quad \mathrm{~F}=$ Local Froude number

$9 \quad$ g gravity acceleration

$10 h$ water depth

$11 k$ non-dimensional coefficient in viscosity calculation

$12 n$ Manning's roughness coefficient

$13 u$ velocity along horizontal $x$-axis,

$14 u^{*}$ bottom friction velocity

$15 v$ velocity along horizontal $y$-axis,

$16 \quad z_{b}$ bottom level

$17 v_{e f}$ effective kinematic viscosity.

$18 \sigma=$ Standard deviation

19 


\section{References}

Aronica, G.T. and Lanza, L.G., 2005. Drainage efficiency in urban areas: a case study. Hydrological Processes, 19.

BCEOM, CS and Météo France, 2004. Outil de prévision hydrométéorologique - Projet Espada - Ville de Nîmes (Technical report in French).

Bonneaud, S., 2002. Nîmes, du 3 octobre 1988 au Plan de Protection Contre les Inondations (CD rom), Publisher : Agropolis International, Proceeding of conference : "Inondations en France", Montpellier, France (in French).

Calenda, G., Calvani, L. and Mancini, C.P., 2003. Simulation of the great flood of December 1870 in Rome. Water and Maritime Engineering, 156(4).

Chen, H.H., HSU, M.H. and Chen, T.S., 2004. The integrated inundation model for urban drainage basins, Novatech 2004, Lyon, France.

Desbordes, M., Durepaire, P., Gilly, J.C., Masson, J.M. and Maurin, Y., 1989. 3 Octobre 1988: Inondations sur Nîmes et sa Région: Manifestations, Causes et Conséquences (in French). Publisher : C. Lacour, Nîmes France.

Gourbesville, P. and Savioli, J., 2002. Urban runoff and flooding : interests and difficulties of the 2D approach, 5th international Hydroinformatics (2002), Cardiff, UK.

Haider, S., 2001. Contribution à la modélisation d'une inondation en zone urbanisée. Approche bidimensionnelle par les équations de Saint Venant (in French). (Contribution to the modelling of a flood in an urbanised zone - 2-D approach by de Saint Venant equations) . Ph D Thesis, Institut National des Sciences Appliquées, Lyon.

Haider, S., Paquier, A., Morel, R. and Champagne, J.-Y., 2003. Urban flood modelling using computational fluid dynamics. Water and Maritime Engineering, 156(2).

Hsu, M.H., Chen, S.H. and Chang, T.J., 2000. Inundation simulation for urban drainage basin with storm sewer system. Journal of hydrology, 234.

Huang, J.C., Weber, L.J. and Lai, Y.G., 2002. Three-dimensional numerical study of flows in openchannel junctions. Journal of Hydraulic Engineering-Asce, 128(3).

Inoue, K., Kawaike, K. and Hayashi, H., 2000. Numerical simulation models of inundation flow in urban area. Journal of Hydroscience and Hydraulic Engineering, 18(1).

Ishigaki, T., Nakagawa, H. and Baba, Y., 2004. Hydraulic model test and calculation of flood in urban area with underground space, Environmental Hydraulics and Sustainable Water ManagementLee \& Lam (eds) : Volume 2, Sustainable Water Management in the Asia-Pacific Region, A.A. Balkema Publishers.

Khan, A.A., Cadavid, R. and Wang, S.S.Y., 2000. Simulation of channel confluence and bifurcation using the CCHE2D model. Water and Maritime Engineering, 142.

Mark, O., Weesakul, S., Apirumanekul, C., Aroonnet, S.B. and Djordjevic, S., 2004. Potential and limitations of 1D modelling of urban flooding. Journal of hydrology, 299.

Mignot, E. and Paquier, A., 2003a. Impact - Flood propagation case study - The model city flooding experiment, 3rd IMPACT Worshop (EU-funded research project on Investigation of Extreme Flood Processes and Uncertainty), Louvain La Neuve, Belgium. 5-7 November 2003. Publisher : HR Wallingford.

Mignot, E. and Paquier, A., 2003b. Impact - Flood propagation. Isolated building test case, 3rd IMPACT Worshop (EU-funded research project on Investigation of Extreme Flood Processes and Uncertainty), Louvain La Neuve, Belgium, 5-7 November 2003. Publisher : HR Wallingford.

Mignot, E. and Paquier, A., 2004. Impact-Flood propagation case study. The flooding of Sumacárcel after Tous Dam Break. Cemagref's modelling, 4th IMPACT Workshop (EU-funded research project on Investigation of Extreme Flood Processes and Uncertainty), Zaragoza, Spain, 3-5 November 2004. Publisher : HR Wallingford. 
Mignot, E., Paquier, A., Perkins, R.J. and Rivière, N., 2005a. Flow structures at the junction of four supercritical channel flows, 10th International Conference on Urban Drainage, Copenhagen, Denmark, 21-26 August 2005.

Mignot, E., Paquier, A. and Rivière, N., 2005b. 2D numerical simulation of four branches experimental supercritical junction flows, XXXI IAHR Congress, 11th - 16th September 2005, Seoul, Korea.

Nania, L.S., 1999. Metodologia numérico-experimental para el analisis del riesgo asociado a la escorrentia pluvial en una red de calles. $\mathrm{PhD}$ Thesis, Universitat politècnica de Catalunya, Barcelona (in Spanish).

Neary, V.S., Sotiropoulos, F. and Odgaard, A.J., 1999. Three-dimensional numerical model of lateralintake inflows. Journal of Hydraulic Engineering, 125(2): 126-140.

Paquier A., 1995. Modélisation et simulation de la propagation de l'onde de rupture de barrage (in French) (Modelling and simulating the propagation of dam-break wave). $\mathrm{PhD}$ Thesis, Université Jean Monnet de Saint Etienne.

Paquier A., 1998. 1-D and 2-D models for simulating dam-break waves and natural floods. In : Concerted action on dam-break modelling, processings of the CADAM meeting (ed. by M.Morris, J.-C. Galland, and P. Balabanis). European Commission, Science Research Development, Hydrological and hydrogeological risks, Luxembourg.

Perrin, C., Michel, C. and Andreassian, V., 2003. Improvement of a parsimonious model for streamflow simulation. Journal of hydrology, 279(1-4).

Schmitt, T.G., Thomas, M. and Ettrich, N., 2004. Analysis and modeling of flooding in urban drainage systems. Journal of hydrology, 299.

Shettar, A.S. and Murthy, K.K., 1996. A numerical study of division of flow in open channels. Journal of Hydraulic Research, 34(5).

VanLeer B., 1979. Towards the ultimate conservative difference scheme. V.A second order sequel to Godunov's method. Journal of computational physics, 32.

Weber, L.J., Schumate, E.D. and Mawer, N., 2001. Experiments on flow at a $90^{\circ}$ open-channel junction. Journal of Hydraulic Engineering, 127(5). 
3 Figure 1 : "Richelieu" area of the city of Nîmes with $S_{1}$ to $S_{11}$ the outlets from the area

$4 \quad$ Figure 2 : 11-points street section profile

$5 \quad$ Figure 3 : East and West hydrographs at the studied area border for the 1988 flood.

$6 \quad$ Figure 4 : Supercritical and subcritical flow regimes at the peak of the flood

7 Figure 5: Water depths at the flood peak and limit of flooded area (in dot lines)

8 Figure 6: Map of comparison between computed peak water depths and measured flood

9 marks with $d h=H_{m a x}$ computed $-H_{m a x}$ measured

$10 \quad$ Figure 7 : Histogram of peak water depth prediction error.

11 Figure 8 : Limnigrams at point P1(Figure 1) for various parameter set cases.

12 Figure 9 : Flow regime patterns at the flood peak $(\mathrm{t}=4.1$ hours $)$ in one crossroad for Reference 13 case and Case 2B

14 Figure 10 : Limnigrams computed at the comparison cell of Figure 9 for Reference case and 15 Case 2B.

16 Figure 11 : Comparison between the reference case and Case 3B computed water depths in

17 the Central and Southern zones of the domain with $\mathrm{dh}=\mathrm{h}_{3 \mathrm{~B}}-\mathrm{h}_{\text {reference. }}$

18 Figure 12 : Increase in water depth using a flat profile description

19 Figure $13: 7-5$ - and 4-points simplified profiles

20 Figure 14 : Comparison between flood mark and computed peak water depth for reference 21 and 4-points cross-section calculation at supercritical small scale zones of the crossroads

22 Figure 15 : Comparison of flow rate distribution in the downstream end streets for reference 23 and 4-points cases.

24 Figure 16: Flood hydrograph for September 2002 flood event after subtracting the sewer 25 capacities. 
1 Figure 17 : Comparison between peak water depths and measured flood marks 2

3 
2 Table legends

3 Table 1 : Comparison between computed and measured peak water depth for the reference

4 case and some important parameters modification. $\overline{d h}$ is the average difference between

5 computed and measured peak water depths: $\overline{d h}=\frac{\sum d h}{n}=\frac{\sum\left(H_{\text {computed }}-H_{\text {measured }}\right)}{n}$ with $\mathrm{H}_{\text {measured }}$

6 the flood mark measurement, $H_{\text {computed }}$ the computed peak water depth in the nearest cell and $n$

7 is the number of flood marks (99 in this case). $\sigma_{\mathrm{dh}}$ is the standard deviation of $\mathrm{dh}$ :

$8 \sigma_{d h}=\sqrt{\frac{\sum(d h-\overline{d h})^{2}}{n}}$

9 Table 2 : Impact of the main parameters in the sensitivity analysis with :

10 (1) = Global change of peak water depths (with $\uparrow=$ increase and $\downarrow=$ decrease of peak water depth)

11 (2) = Change in flow distribution at Faita/Sully crossroad and to the downstream limit areas

$12 \quad(3)=$ Local flow regime change

13

14 
$1 \quad$ Figures

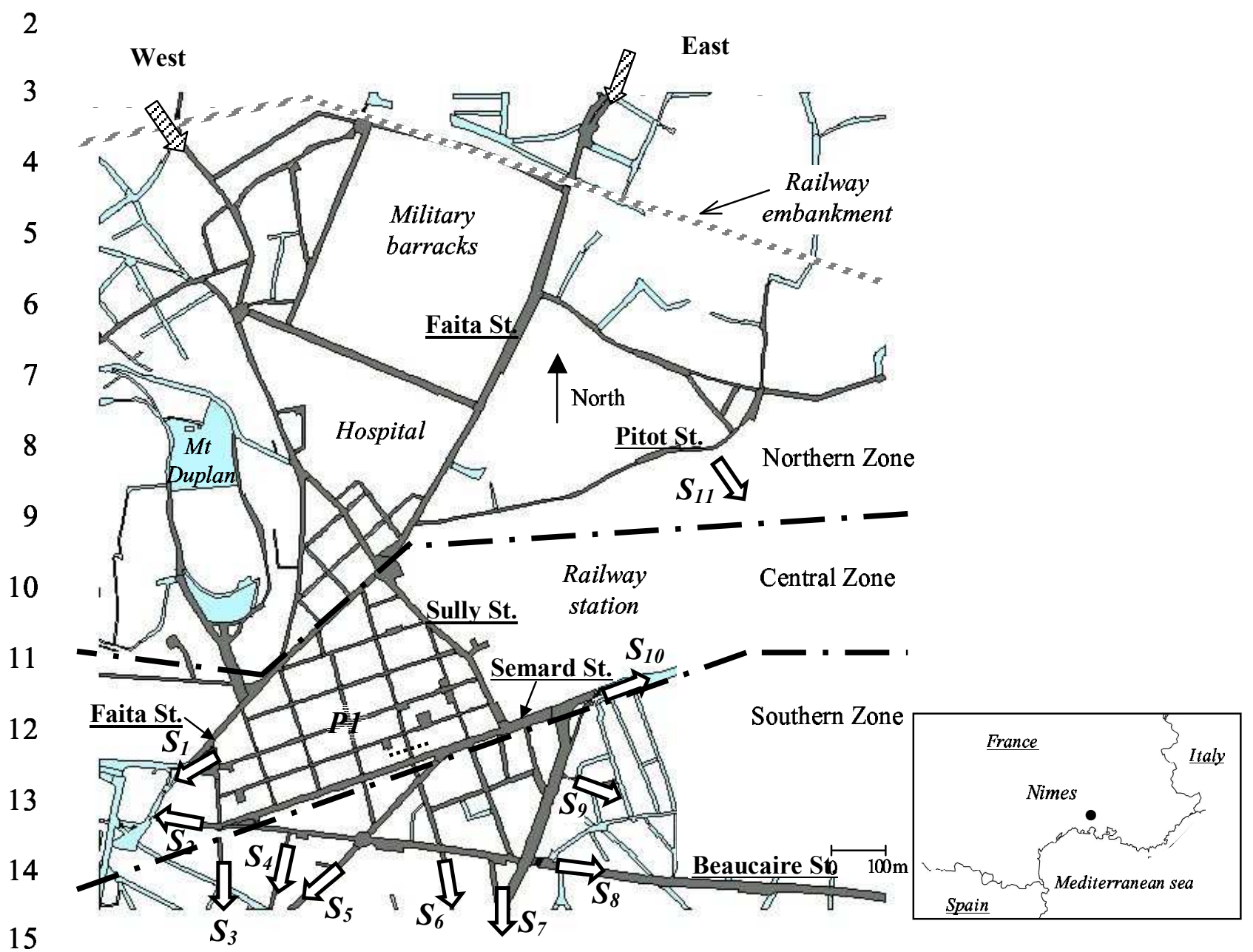

16 Figure 1: "Richelieu" area of the city of Nimes with $S_{1}$ to $S_{11}$ the outlets from the area

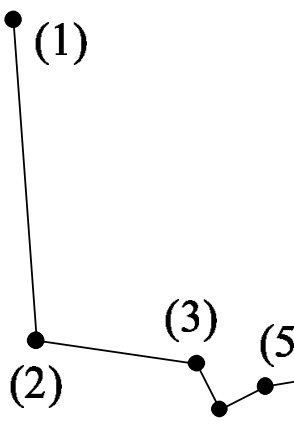

(4)
(6)

(5)

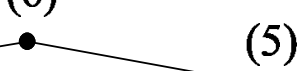

(5)

(4)

(3)

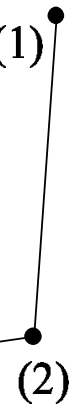

Figure 2 : 11-points street section profile 


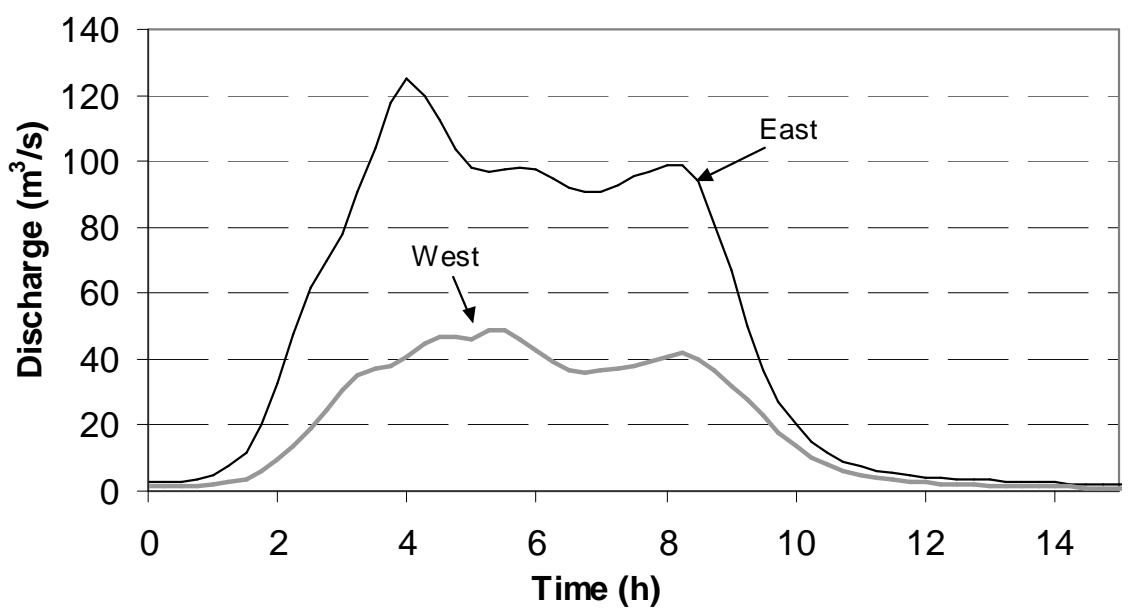

2

3 Figure 3 : East and West hydrographs at the studied area border for the $1988 \mathrm{flood}$.

4

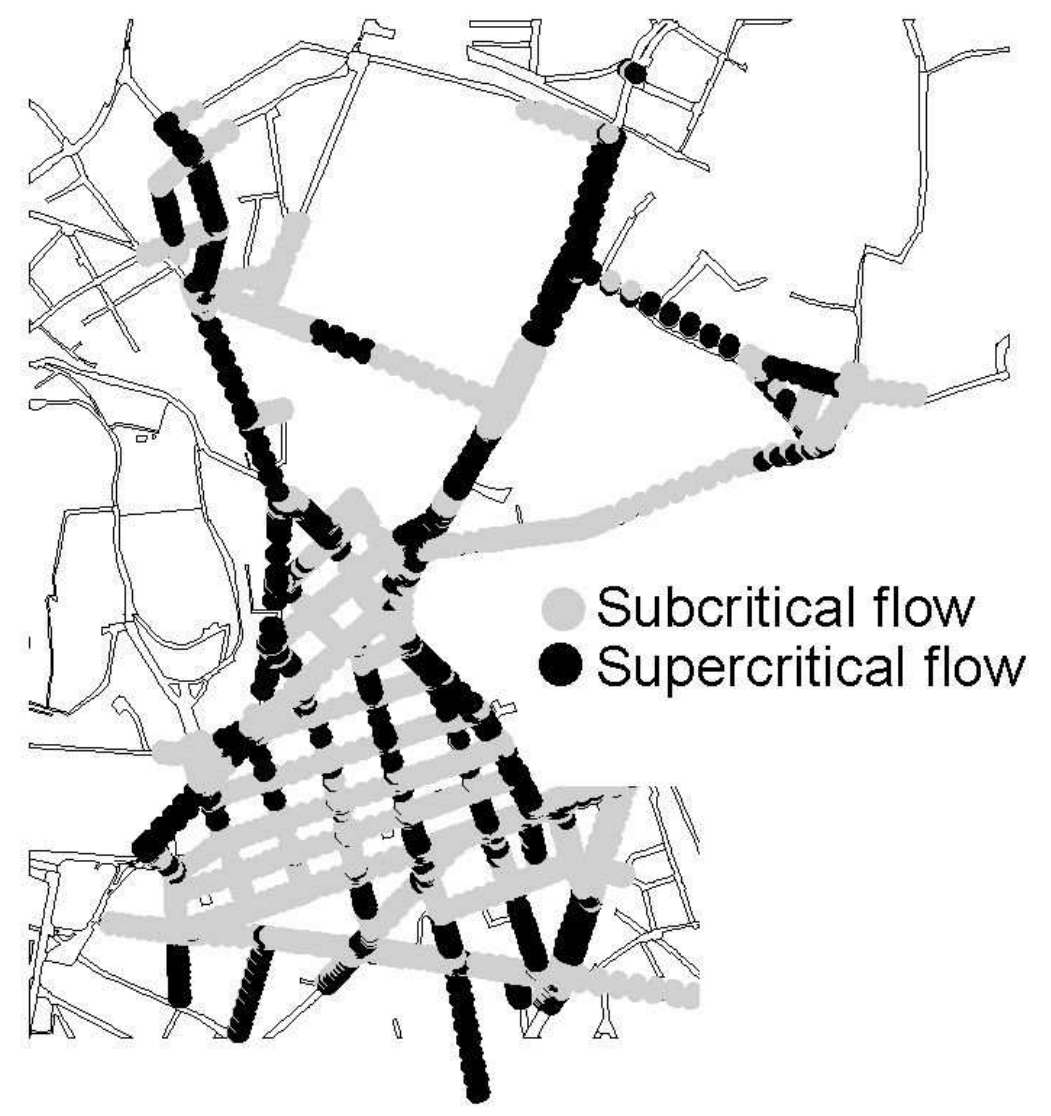

5

$6 \quad$ Figure 4 : Supercritical and subcritical flow regimes at the peak of the flood 


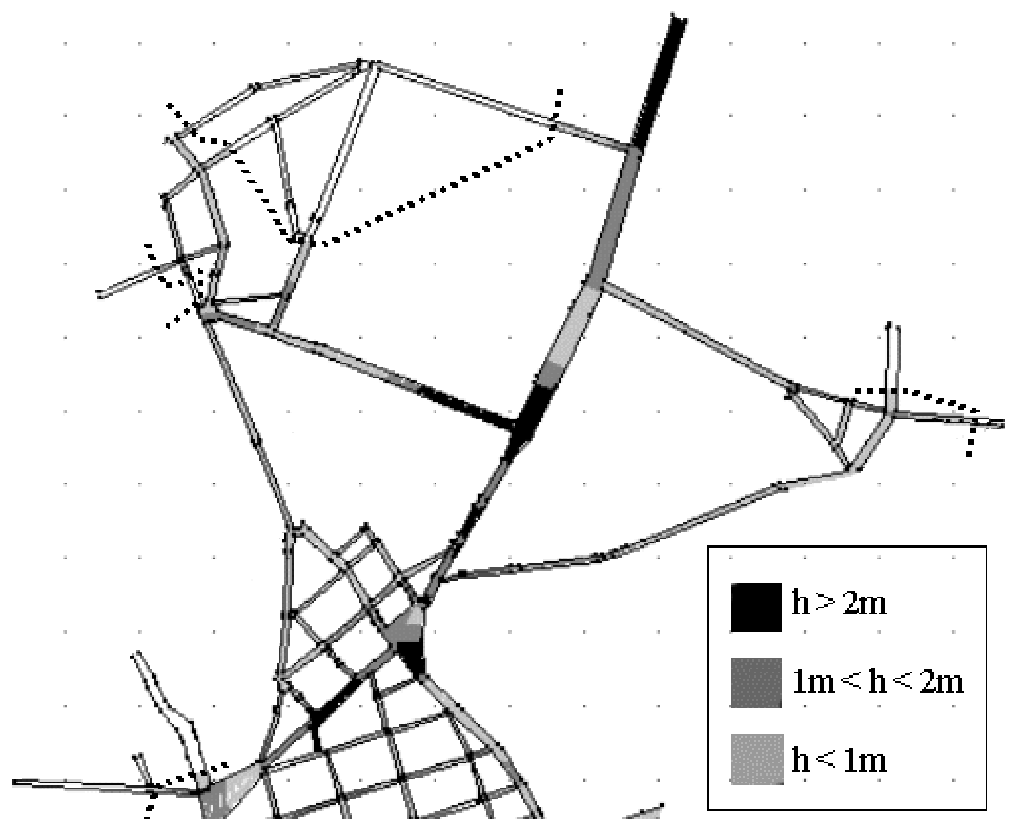

2

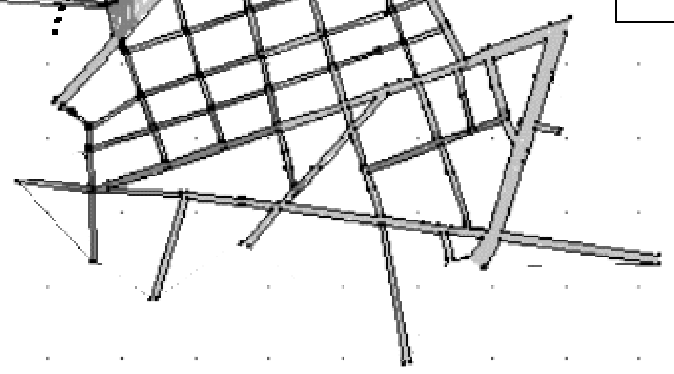

3 Figure 5: Water depths at the flood peak and limit of flooded area (in dot lines)

4

5

6

7

8

9

10

11 


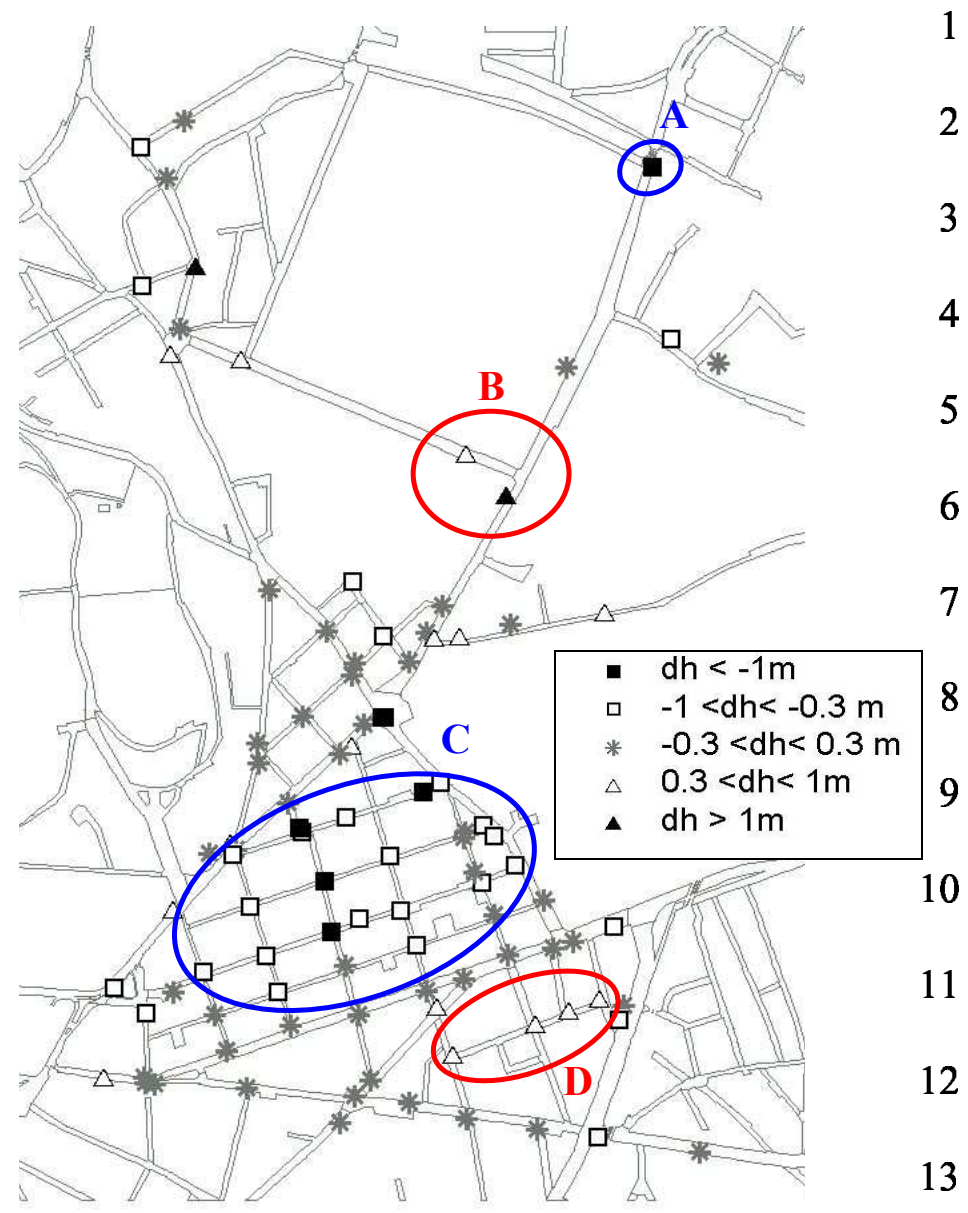

14

15 Figure 6: Map of comparison between computed peak water depths and measured flood marks with $16 \mathrm{dh}=\mathrm{Hmax}_{\text {computed }}-\mathrm{Hmax}_{\text {measured }}$

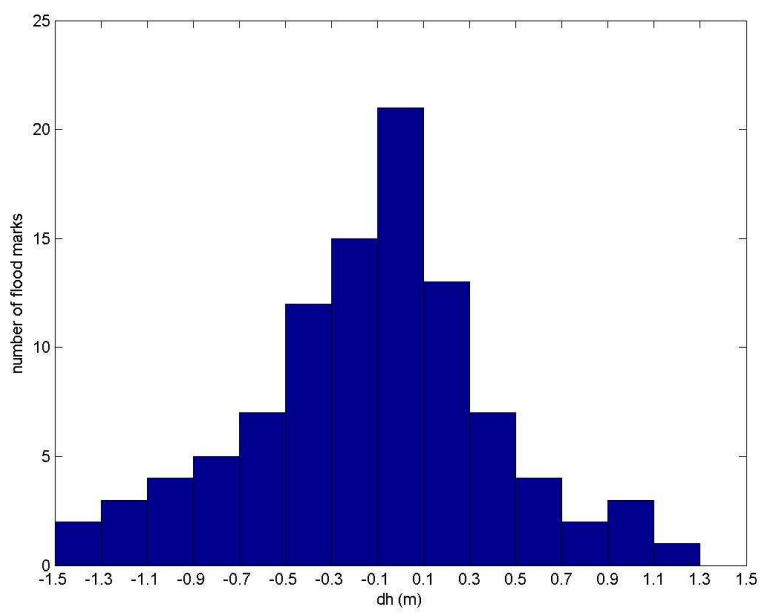


1 Figure 7 : Histogram of peak water depth prediction error.

2

3

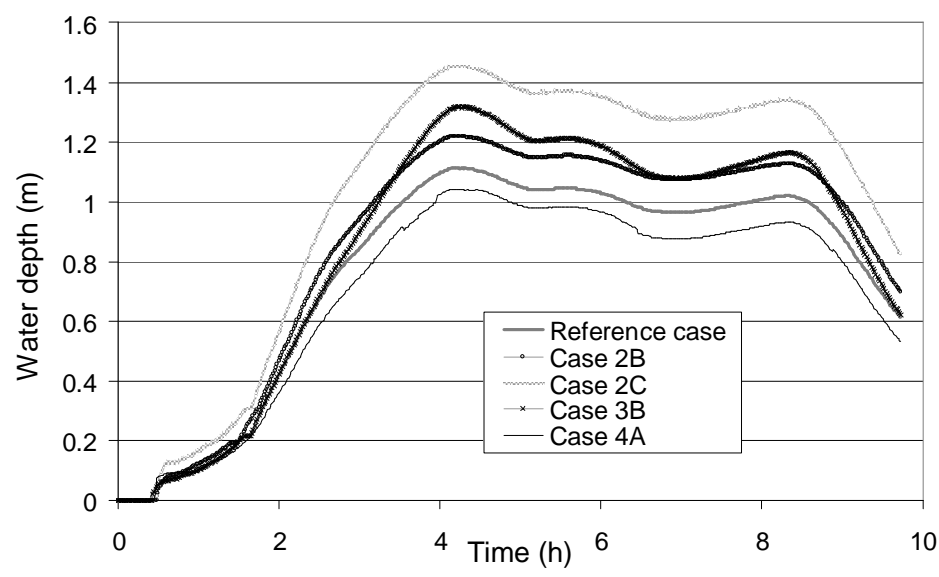

$4 \quad$ Figure 8: Limnigrams at point P1(Figure 1) for various parameter set cases.

5
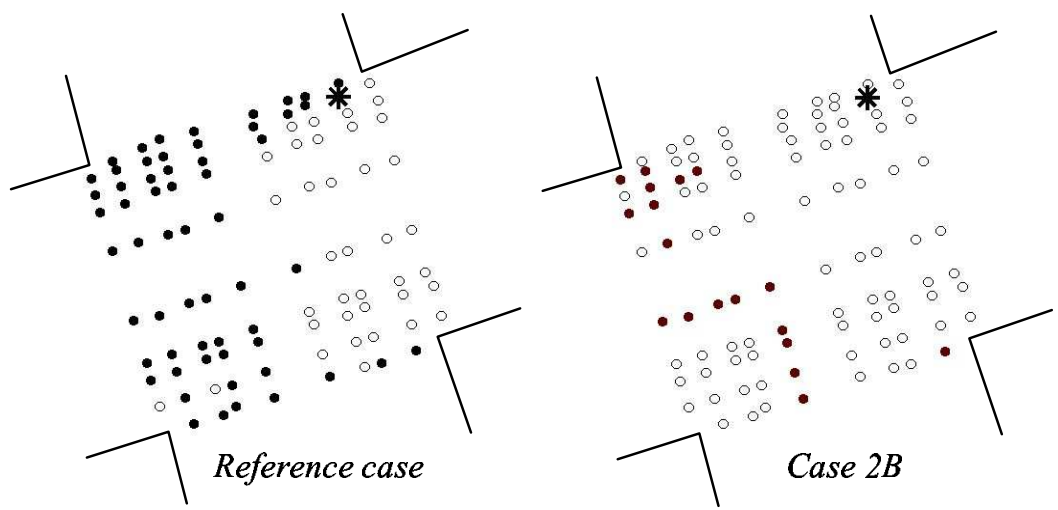

Subcritical

- Supercritical

* Comparison cell

6 Figure 9: Flow regime patterns at the flood peak ( $t=4.1$ hours) in one crossroad for Reference case and Case $7 \quad 2 B$

8

9

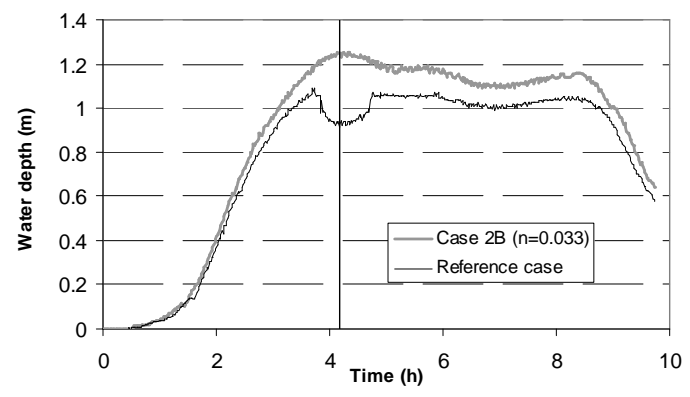


1 Figure 10: Limnigrams computed at the comparison cell of Figure 9 for Reference case and Case $2 B$.

2

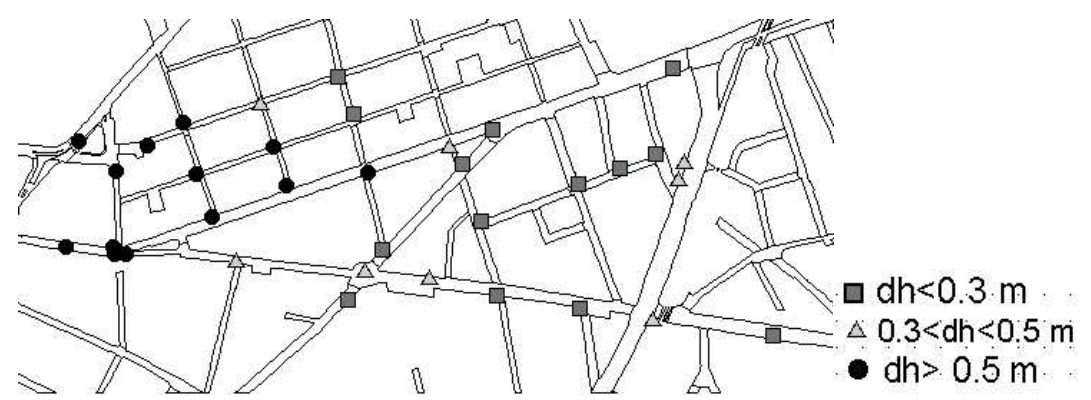

$4 \quad$ Figure 11: Comparison between the reference case and Case $3 B$ computed water depths in the Central and

5 Southern zones of the domain with $d h=h_{3 B}-h_{\text {reference. }}$

6
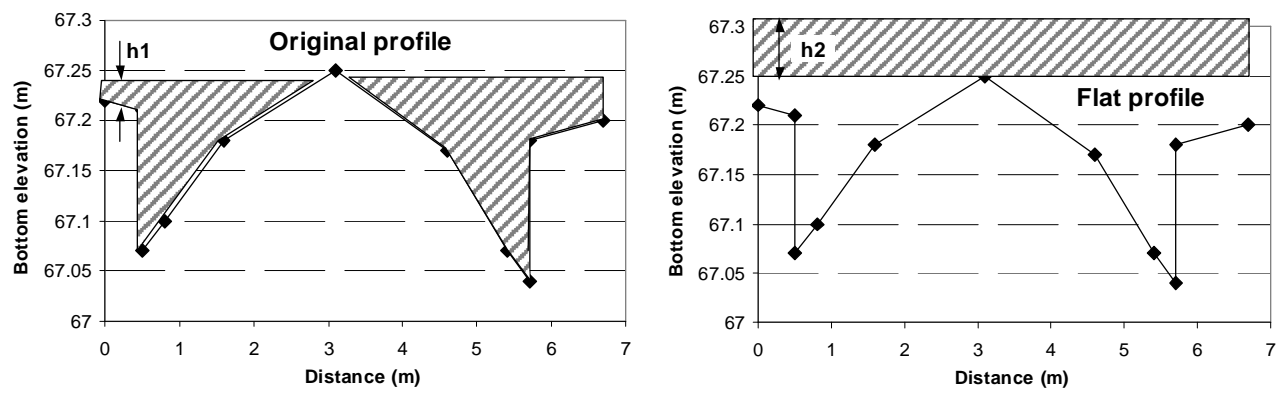

8 Figure 12 : Increase in water depth using a flat profile description

9
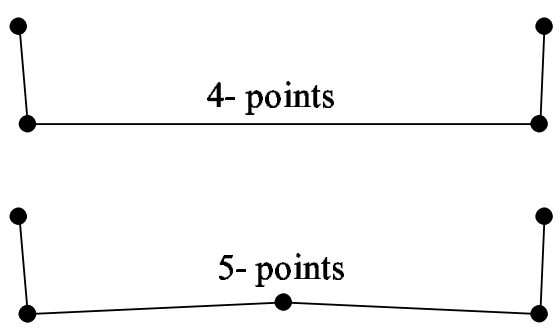

10

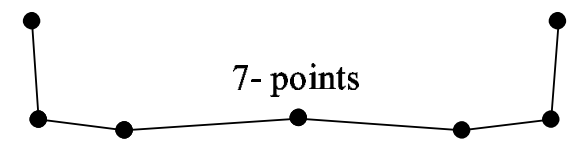

11 Figure 13 : 7- 5- and 4-points simplified profiles 


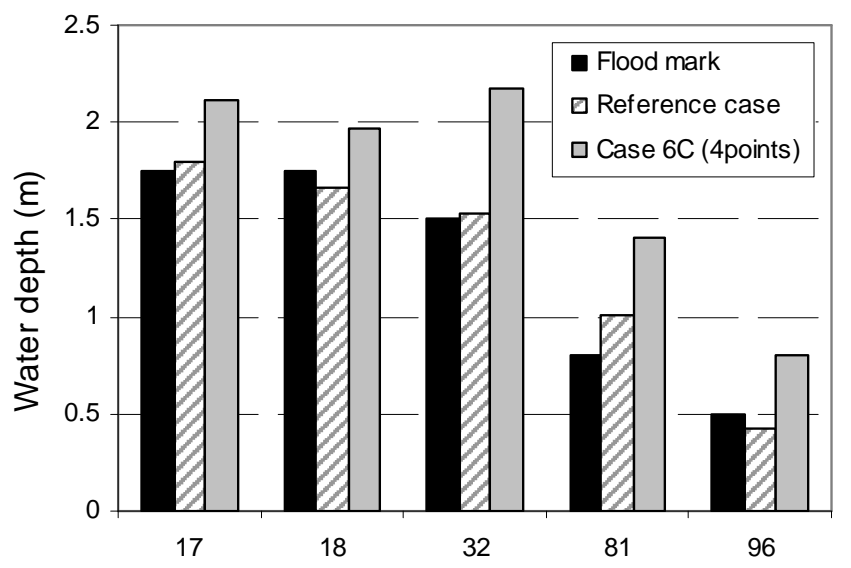

1

Flood mark number

$2 \quad$ Figure 14 : Comparison between flood mark and computed peak water depth for reference and 4-points cross-

3 section calculation at supercritical small scale zones of the crossroads

4

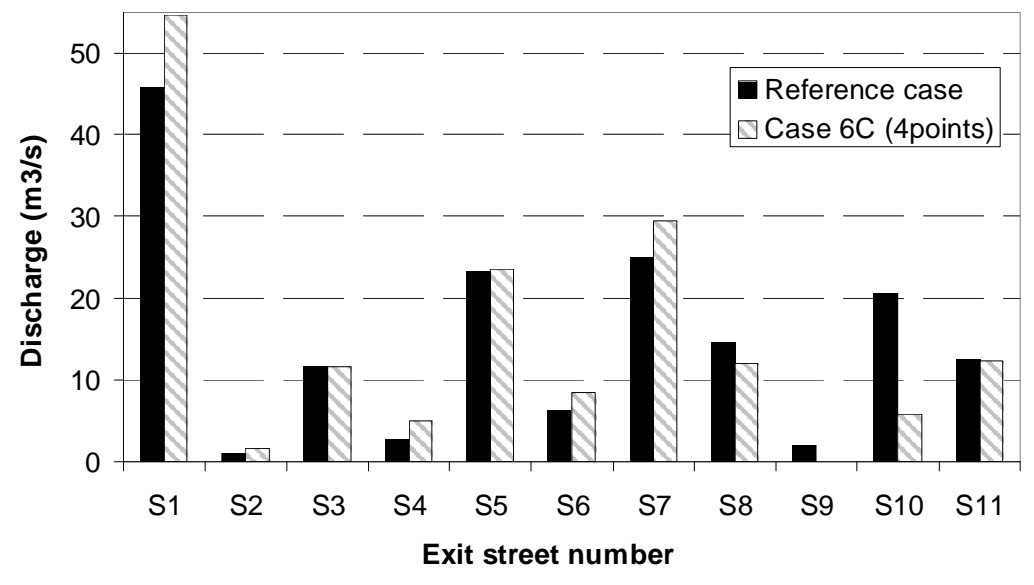

6 Figure 15 : Comparison of flow rate distribution in the downstream end streets for reference and 4-points cases.

7 


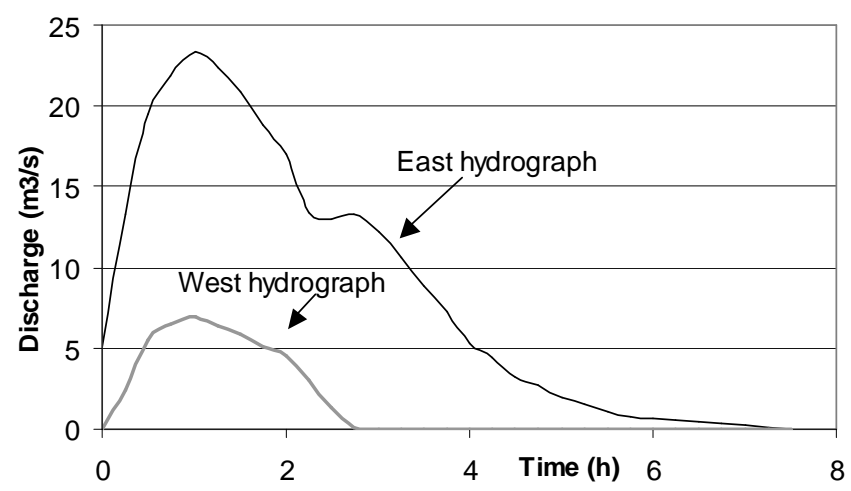

2 Figure 16 : Flood hydrograph for September 2002 flood event after subtracting the sewer capacities.

3

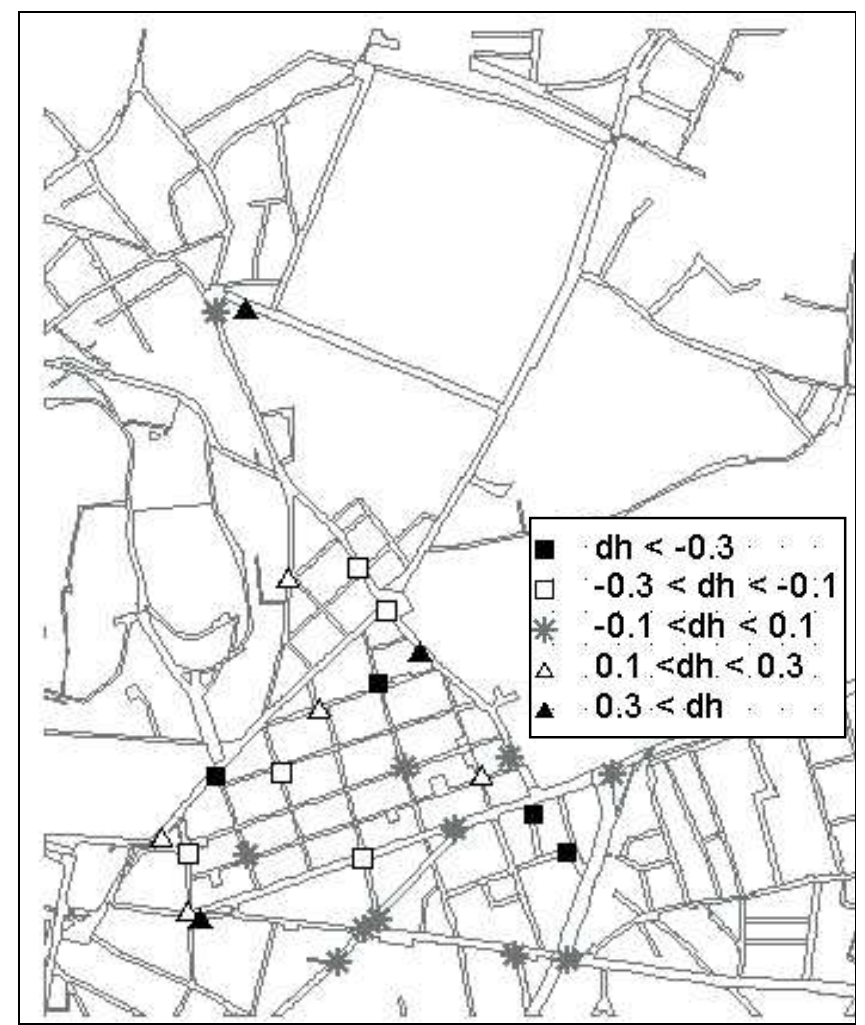

15 Figure 17 : Comparison between peak water depths and measured flood marks 
1 Tables

2

\begin{tabular}{|c|c|c|c|c|c|}
\hline & \multirow{3}{*}{$\begin{array}{c}\text { Northern zone } \\
0.04\end{array}$} & & & \\
\hline & & & \multirow{2}{*}{$\begin{array}{c}\text { Central zone } \\
-0.43\end{array}$} & \multirow{2}{*}{$\begin{array}{c}\text { Southern zone } \\
0.13\end{array}$} & \multirow{2}{*}{$\begin{array}{c}\text { Whole domain } \\
-0.13\end{array}$} \\
\hline \multirow{2}{*}{ Reference case } & $\overline{d h}(\mathrm{~m})$ & & & & \\
\hline & $\sigma_{\mathrm{dh}}(\mathrm{m})$ & 0.56 & 0.54 & 0.43 & 0.53 \\
\hline \multirow{2}{*}{$\begin{array}{l}\text { Case 2B } \\
n=0.033\end{array}$} & $\overline{d h}(\mathrm{~m})$ & 0.17 & -0.35 & 0.17 & -0.04 \\
\hline & $\sigma_{\mathrm{dh}}(\mathrm{m})$ & 0.57 & 0.54 & 0.44 & 0.53 \\
\hline \multirow{2}{*}{$\begin{array}{c}\text { Case 2C } \\
\mathrm{n}=0.025 \& \mathrm{n}=0.05\end{array}$} & $\overline{d h}(\mathrm{~m})$ & 0.06 & -0.23 & 0.14 & -0.04 \\
\hline & $\overline{\sigma_{\mathrm{dh}}(\mathrm{m})}$ & 0.54 & 0.46 & 0.39 & 0.48 \\
\hline \multirow{2}{*}{$\begin{array}{c}\text { Case 3B } \\
\text { S1, S2, S10 off }\end{array}$} & $\overline{d h}(\mathrm{~m})$ & 0.05 & -0.19 & 0.49 & 0.05 \\
\hline & $\sigma_{\mathrm{dh}}(\mathrm{m})$ & 0.54 & 0.68 & 0.58 & 0.61 \\
\hline \multirow{2}{*}{$\begin{array}{c}\text { Case 6B } \\
\text { 5-points/ section }\end{array}$} & $\overline{d h}(\mathrm{~m})$ & 0.01 & -0.36 & 0.29 & -0.08 \\
\hline & $\sigma_{\mathrm{dh}}(\mathrm{m})$ & 0.54 & 0.51 & 0.54 & 0.53 \\
\hline \multirow{2}{*}{$\begin{array}{c}\text { Case 6C } \\
\text { 4-points / section }\end{array}$} & $\overline{d h}(\mathrm{~m})$ & 0.07 & -0.45 & 0.22 & -0.11 \\
\hline & $\sigma_{\mathrm{dh}}(\mathrm{m})$ & 0.64 & 0.7 & 0.56 & 0.65 \\
\hline
\end{tabular}

3 Table 1: Comparison between computed and measured peak water depth for the reference case and some

4 important parameters modification. $\overline{d h}$ is the average difference between computed and measured peak water

5 depths: $\overline{d h}=\frac{\sum d h}{n}=\frac{\sum\left(H_{\text {computed }}-H_{\text {measured }}\right)}{n}$ with $H_{\text {measured }}$ the flood mark measurement, $H_{\text {computed }}$ the

6 computed peak water depth in the nearest cell and $n$ is the number of flood marks ( 99 in this case). $\sigma_{d h}$ is the

7 standard deviation of $d h: \sigma_{d h}=\sqrt{\frac{\sum(d h-\overline{d h})^{2}}{n}}$

8

9 


\begin{tabular}{|c|c|c|c|c|}
\hline Parameter modification & (1) & (2) & (3) & Other impacts and remarks : \\
\hline $\begin{array}{l}\text { Increase input hydrographs } \\
\text { Case } 1 A\end{array}$ & $\mathrm{X}(\uparrow)$ & & & $\begin{array}{l}\text { Average increase of } 12.5 \mathrm{~cm} \text { if the flow } \\
\text { rates are increased by } 20 \%\end{array}$ \\
\hline $\begin{array}{l}\text { Increase friction coefficient } \\
\text { Case } 2 B\end{array}$ & $\mathrm{X}(\uparrow)$ & $\mathrm{X}$ & $\mathrm{X}$ & \\
\hline $\begin{array}{l}\text { Friction coefficient defined by zone } \\
\text { Case } 2 C\end{array}$ & & & & $\begin{array}{l}\text { The calibrated coefficient value improves } \\
\text { the results in every zone }\end{array}$ \\
\hline $\begin{array}{l}\text { Change of downstream boundary } \\
\text { condition numerical treatment } \\
\text { Case } 3 A\end{array}$ & & & & $\begin{array}{l}\text { Modification of discharge distribution in } \\
\text { the downstream streets }\end{array}$ \\
\hline $\begin{array}{l}\text { Backwater effects from downstream } \\
\text { zones : Blocking some exit streets. } \\
\text { Case } 3 B\end{array}$ & & & & $\begin{array}{c}\text { Global flow modifications in the whole } \\
\text { Southern area }\end{array}$ \\
\hline $\begin{array}{c}\text { Flat street profile } \\
\text { Case } 4 A \\
\end{array}$ & $X(\uparrow)$ & & $\mathrm{X}$ & $\begin{array}{l}\text { Similar increase of water depth in the three } \\
\text { zones compared to Reference case }\end{array}$ \\
\hline $\begin{array}{c}\text { Simplified main crossroad } \\
\text { Case } 4 B \\
\end{array}$ & & $\mathrm{X}$ & & $\begin{array}{l}\text { Backwater effects upstream from the } \\
\text { crossroad \& flow pattern modifications }\end{array}$ \\
\hline $\begin{array}{c}\text { Local obstacle } \\
\text { Case } 4 C \\
\end{array}$ & & & & $\begin{array}{l}\text { Strong local effects and slight downstream } \\
\text { consequences }\end{array}$ \\
\hline $\begin{array}{c}\text { Simplified longitudinal mesh } \\
\text { Case } 5 \mathrm{~A}\end{array}$ & & $\mathrm{X}$ & $\mathrm{X}$ & $\begin{array}{c}\text { Modification of backwater effects in } \\
\text { downstream filling zones }\end{array}$ \\
\hline $\begin{array}{c}\text { Simplified street profile ( } 4 \& 5- \\
\text { points cross-sections) } \\
\text { Cases } 6 B \text { and } 6 C\end{array}$ & $X(\uparrow)$ & $\mathrm{X}$ & $\mathrm{X}$ & $\begin{array}{l}\text { Simplification of the flow patterns in the } \\
\text { street junctions }\end{array}$ \\
\hline $\begin{array}{c}\text { Considering the rain } \\
\text { Case } 1 B\end{array}$ & $X(\uparrow)$ & & & $\begin{array}{l}\text { Limited impact due to small rain volumes } \\
\text { compared to input hydrographs }\end{array}$ \\
\hline $\begin{array}{l}\text { Considering the storage areas } \\
\text { Case } 1 C\end{array}$ & $X(\downarrow)$ & & & $\begin{array}{l}\text { Limited impact due to small volumes stored } \\
\text { compared to input hydrographs }\end{array}$ \\
\hline $\begin{array}{c}\text { Diffusion coefficient } \\
\text { Case } 2 A \\
\end{array}$ & & & $\mathrm{X}$ & Limited impact \\
\hline $\begin{array}{c}\text { Neglecting gutters (7-points cross- } \\
\text { sections) } \\
\text { Case } 6 A\end{array}$ & $\mathrm{X}(\uparrow)$ & & & Limited impact \\
\hline
\end{tabular}

2 Table 2: Impact of the main parameters in the sensitivity analysis with : 